\title{
EFFECT OF THE TYPE OF HEAT SOURCES ON CARBON DIOXIDE EMISSIONS
}

\author{
Sławomir Rabczak', Danuta Proszak-Miąsik ${ }^{1}$ \\ 1 Faculty of Civil, Environmental Engineering and Architecture, Rzeszow University of Technology, Rzeszow, \\ Poland, e-mail: rabczak@prz.edu.pl; dproszak@prz.edu.pl
}

Received: 2016.08.11 Accepted: 2016.09.26 Published: 2016.11.01

\begin{abstract}
A lot of attention is nowadays devoted to the problem of generally defined ecology. It is absolutely essential in case of systems and sources generating heat due to their direct influence on the environment through emitting post-process products to the atmosphere which are, most frequently a result of combustion. Therefore, constant searchers are made to optimize the operation of heat sources and to acquire energy from sources for which the general balance of carbon dioxide emission is zero or close to zero. This work compares the emissions of equivalent $\mathrm{CO}_{2}$ from selected systems with the following heat sources: coal, gas furnace, heat pump, and refers results of the analysis to aspects connected with regulations concerning environmental protection. The systems generating thermal energy in the gas furnaces, coal, biomass, as well as the compression heat pumps with the lower heat source as ambient air or ground were taken under consideration, as well as centralized systems for the production of heat based on the combustion of coal, gas, oil, and biomass. the Emission of carbon dioxide for the installation of cogeneration and absorption heat pump were also calculated. Similarly obtained amount of extra emission necessary for the proper operation maintenance of heating devices via the supplied electricity from external source, the mostly fuel-fired power plants for fuels as previously mentioned. The results of the calculations were presented in tables and graphs.
\end{abstract}

Keywords: $\mathrm{CO}_{2}$ emission, heat pump, heat source, greenhouse gases

\section{INTRODUCTION}

One of the criteria for choosing an energy source is the emission of pollution and the influence of the system on the environment. Toughening up regulations in the European Union and the bias towards minimization of the emission of pollution make it a key problem with regard to environmental protection (Macknick. J. 2011). There is a wide variety of heating systems for detached houses. They are comprehensive solutions based on highly effective techniques of fuel combustion or energy carriers' usage. Gas or oil condensing furnaces allow to obtain highest operating efficiencies.

A heating system should be effective, comfortable in usage, and, above all, it should have low operating costs and should be harmful to the natural environment in the smallest possible degree.

Solid fuel furnaces are one of the cheapest heating systems available on the market. These are their low operating costs which make them so popular. However, they have several serious disadvantages. They include fuel storage, loading up fuel into the furnace and disposing of combustion residues.

A greater interest in these types of furnaces for the recent years has made their producers to undertake intensive works aiming at more effective and ecological combustion of solid fuels. Improved and automated constructions, their high efficiency and easier operation of its contribute to their greater and greater popularity.

Newly constructed residential buildings are now equipped with connections to gas grids. 
So, making use of this efficient source of energy seems obvious. Good points of using gas are that the combustion process is friendly to the environment, a slight amount of residues remains in the furnace, and consequently, cleaning and maintenance are quite cheap. Additionally, a gas boiler does not require much space. So it can be installed in a flat or a utility room. A special, separate room is not necessary.

Heat pumps consume huge amounts of thermal energy which are kept in natural deposits. A design of a heat pump enables it to acquire thermal energy from various kinds of sources, i.e. from soil, air or water. Due to its low temperature, such sources are not fit for direct usage but thanks to a heat pump it is possible to acquire energy from them.

\section{CARBON DIOXIDE EMISSIONS FROM SELECTED SYSTEMS}

The aim of this project is to determine the volume of $\mathrm{CO}_{2}$ emitted to the atmosphere by a heating system in a residential building. It was assumed that the heating system will serve only to meet the demand for heat and to compensate for the heat loss caused by transmission and ventilation. It was assumed that the building has natural ventilation and a heat source in a form of:

- coal-fired furnace,

- gas-fired furnace,

- gas condensing furnace,

- air-water heat pump,

- brine-water heat pump,

- biomass furnace,

- oil furnace,

- micro-cogeneration,

- absorption heat pump.

Additionally, heat from the heat distribution network where heat is produced from combustion of the following fuels may be supplied to the building:

- coal,

- gas,

- oil,

- biomass.

The seasonal heat consumption was determined according to the Regulation on energy performance certificates, and on that basis, $\mathrm{CO}_{2}$ emissions were calculated.

The designed heat load was calculated according to the EN 12831 standard. The detached house with a heated area of $218.9 \mathrm{~m}^{2}$ and a capacity of $494,3 \mathrm{~m}^{2}$ is located in the zone, with the designed external temperature of $-20^{\circ} \mathrm{C}$ and the average annual external temperature of $7.6^{\circ} \mathrm{C}$. Heat-transfer coefficients of particular partitions of the building meet the requirements for thermal insulation specified in the documentation. The designed heat load of the building is: $\Phi_{H L}=8229 \mathrm{~W}=8,23 \mathrm{~kW}$.

The World Health Organization defines polluted air as air whose chemical constitution may adversely affect the health of humans, plants, animals and other elements of the environment (water, soil). Air pollutions are most dangerous out of all pollutions as they are mobile and may contaminate almost all components of the environment on an extended area.

Carbon dioxide is the main component of gas created as a result of combustion of different types of fuels, especially solid ones.

It is estimated that $\mathrm{CO}_{2}$ is responsible for $75 \%$ of the greenhouse effect, whereas on average, 5 tonnes of $\mathrm{CO}_{2}$ are emitted annually per one inhabitant of Earth. One medium-size tree absorbs approx. $5 \mathrm{~kg}$ of $\mathrm{CO}_{2}$ annually, which means that 1000 trees are needed per one inhabitant to balance the emission of $\mathrm{CO}_{2}$.

According to the European Union Emissions Trading System (EU ETS) the emission volume decrease year by year about $3.5 \%$ average.

Types of heat sources used in heating systems in buildings have a significant influence on the emission of pollution. When burning hard and brown coals, a huge amount of $\mathrm{CO}_{2}$ is liberated, whereas gas produces even half of $\mathrm{CO}_{2}$ generated from coal. When using biomass, such amount is minimal and, additionally, it may be assumed that $\mathrm{CO}_{2}$ remains in the plant's closed circle, so it is a really scanty amount of $\mathrm{CO}_{2}$. The most advantageous example with this regard is

Table 1. The $\mathrm{CO}_{2}$ emission factor in case of combustion of selected fuels (on International Energy Agency, 2015, 2015)

\begin{tabular}{|l|c|}
\hline \multicolumn{1}{|c|}{ Energy source } & $\begin{array}{c}\mathrm{CO}_{2} \text { emmision factor } \mathrm{w}_{\mathrm{CO}_{2}}, \\
\mathrm{~kg} \mathrm{CO}_{2} / \mathrm{GJ}\end{array}$ \\
\hline Black coal & 94.8 \\
\hline Hard coal & 107.3 \\
\hline Gaz & 55.8 \\
\hline Oil & 76.6 \\
\hline Biomas & 109.8 \\
\hline Biogas & 54.3 \\
\hline Atom & 0.0 \\
\hline
\end{tabular}


atomic energy in which case you can say that the emission of $\mathrm{CO}_{2}$ does not occur.

In case of producing additional power for heating system's electrical equipment drives, it was assumed that it is supplied from a power plant which may have an efficiency of $30-40 \%$ if this is a conventional power plant and $80 \%$ if this is a nuclear power plant.

The energy performance of the building was calculated on the basis of formulas included in the regulation on methodology of calculating the energy performance of buildings and flats or parts of buildings which constitute independent technical and functional facilities and on the manner of compiling power performance certificates and their specimens (PN-EN ISO 13790:2008). The effective energy of the analysed building is $\mathrm{Q}_{\text {cnd }}=18194 \mathrm{kWh}$, whereas the length of the heating season is $\mathrm{L}_{\mathrm{h}}=5112 \mathrm{~h}$. Calculation values which have been assumed end energy volumes necessary to be supplied to the thermal shield of the building after taking into account the assumed total efficiencies of the system in the building - see Table 2 .

From Table 2, it appears that centralized systems achieve higher total efficiencies by $10-15 \%$ compared to individual systems due to much greater efficiencies obtained from fuel combustion. They may compete only with systems with heat pumps (if only this factor is taken into consideration as decisive), micro-cogeneration systems due to the availability of so small systems

Table 2. Total system efficiency of the thermal energy source

\begin{tabular}{|c|c|c|}
\hline \multicolumn{2}{|c|}{ Energy source } & Total system efficiency, $\eta_{H, \text { tot }}$ \\
\hline \multirow{7}{*}{ 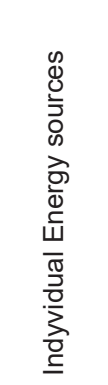 } & coal furnace & 0.63 \\
\hline & gaz furnace & 0.69 \\
\hline & $\begin{array}{l}\text { condensing gaz } \\
\text { furnace }\end{array}$ & 0.73 \\
\hline & $\mathrm{A} / \mathrm{W}$ heat pump & 1.94 \\
\hline & $\mathrm{B} / \mathrm{W}$ heat pump & 2.61 \\
\hline & biomas furnace & 0.51 \\
\hline & oil furnace & 0.69 \\
\hline \multirow{4}{*}{ 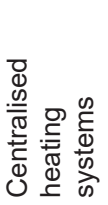 } & coal & 0.81 \\
\hline & gas & 0.88 \\
\hline & oil & 0.85 \\
\hline & biomas & 0.79 \\
\hline \multirow{2}{*}{$\begin{array}{l}\frac{\infty}{\Phi} \\
\frac{5}{0}\end{array}$} & micro-cogeneration & 0.87 \\
\hline & $\begin{array}{l}\text { absorption heat } \\
\text { pump }\end{array}$ & 0.91 \\
\hline
\end{tabular}

adjusted with regard to their efficiency to detached buildings and systems based on absorption heat pumps which do not seem to be an economical solution in residential buildings due to their great costs.

The increased effective energy volume after taking into account total efficiencies of particular systems was presented in Figure 1 in a form of final energy.

Primary and final energy volumes for particular sources of heat supply were determined on the basis of energy production necessary to meet the demand for thermal and electric energy according to the following relationships:

$E_{e l}=E_{p o m}{ }^{*} w_{e l} * 0,0036 \mathrm{GJ} / \mathrm{a}$

$E_{K, H}=Q_{K, H}{ }^{*} w_{K, H} * 0,0036 \mathrm{GJ} / a$

$\mathrm{CO}_{2}$ emissions depending on the efficiency of heat production systems and the manner of generating electric energy were shown in Table 3.

Taking into consideration the above assumptions, final energy EK and primary energy EP rates were established (Fig. 2). It turns out that the common opinion that a heat pump is an ecological heat source is not quite true due to much greater consumption of primary energy compared to other systems. This situation becomes clear if you take into consideration much lower demand for final energy, which translates into low operating costs as noticeable to the user, which does not translate into actual energy consumption nec-

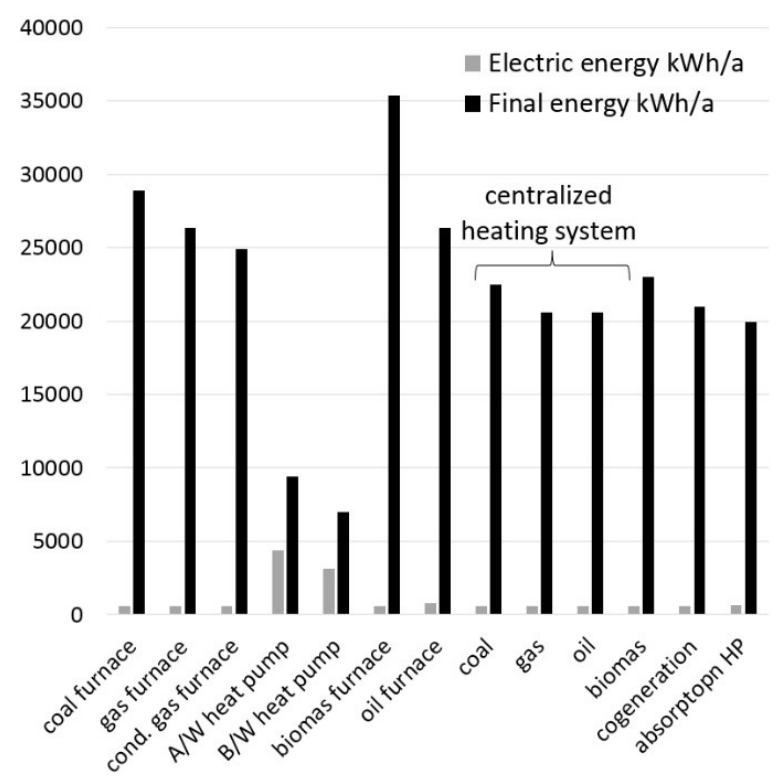

Fig. 1. The size of the final energy $Q_{K, H}$ and electric energy $E_{\text {pom }}$ depending on the energy sources and heating systems. 
Table 3. Production factor of electric and heat energy

\begin{tabular}{|l|c|c|}
\hline \multicolumn{1}{|c|}{ Energy source } & $\begin{array}{c}\text { Heat energy } \\
\mathrm{w}_{\mathrm{K}, \mathrm{H}}\end{array}$ & $\begin{array}{c}\text { Electric energy } \\
\mathrm{w}_{\mathrm{el}}\end{array}$ \\
\hline Coal furnace & 1.22 & \\
\hline Gaz furnace & 1.11 & \\
\hline $\begin{array}{l}\text { Condensing gaz } \\
\text { furnace }\end{array}$ & 1.05 & \\
\hline Oil furnace & 1.11 & 3.0 \\
\hline Biomas furnace & 1.49 & 3.0 \\
\hline $\begin{array}{l}\text { Black coal Power } \\
\text { plant }\end{array}$ & 1.15 & 3.0 \\
\hline $\begin{array}{l}\text { Hard coal Power } \\
\text { Plant }\end{array}$ & 1.15 & 0.7 \\
\hline Gas Power Plant & 1.05 & 3.0 \\
\hline Biogas Power Plant & 1.05 & 3.0 \\
\hline Biomase Power Plant & 1.18 & 3.0 \\
\hline Nuclear Power Plant & 1.01 & 1.1 \\
\hline Oil Power Plant & 1.05 & 3.0 \\
\hline Cogeneration & 1.10 & 1.10 \\
\hline $\begin{array}{l}\text { Absorption heat } \\
\text { pump }\end{array}$ & & \\
\hline
\end{tabular}

essary for the system to operate. The reason for such situation is a small efficiency of systems generating electric energy from conventional energy sources based on the Rankine cycle reaching $45 \%$.

It should be remembered that electric energy is the only energy source necessary for a heat pump system to operate, hence such great differences between primary energy and final one. In such combination, it should be noted that heat distribution systems have smaller annual demand for final energy compared to individual heat sources based on the same fuel. The least popular systems which determine the future of decentralized systems and smaller centralized systems, such as micro-cogeneration, cogeneration and heat pumps with a thermal compressor, achieve smaller indices of annual demand for energy which may lead to their fast development, especially technological one, thus decreasing investment disproportions between the remaining heating systems which presently constitute major barrier to their common usage.

The $\mathrm{CO}_{2}$ emission was determined on the basis of the following relationship:

$$
E_{\mathrm{CO} 2}=E_{e l}{ }^{*} w_{\mathrm{CO} 2}+E_{K, H}{ }^{*} w_{\mathrm{CO}_{2}}, \mathrm{kgCO}_{2} / \mathrm{a}
$$

$\mathrm{CO}_{2}$ emissions from fuel combustion were assumed according to Table 1.

As for biomass, it was assumed that the coal cycle is closed and $\mathrm{w}_{\mathrm{CO} 2}=0$. In case of using compressor heat pumps, the effect connected with

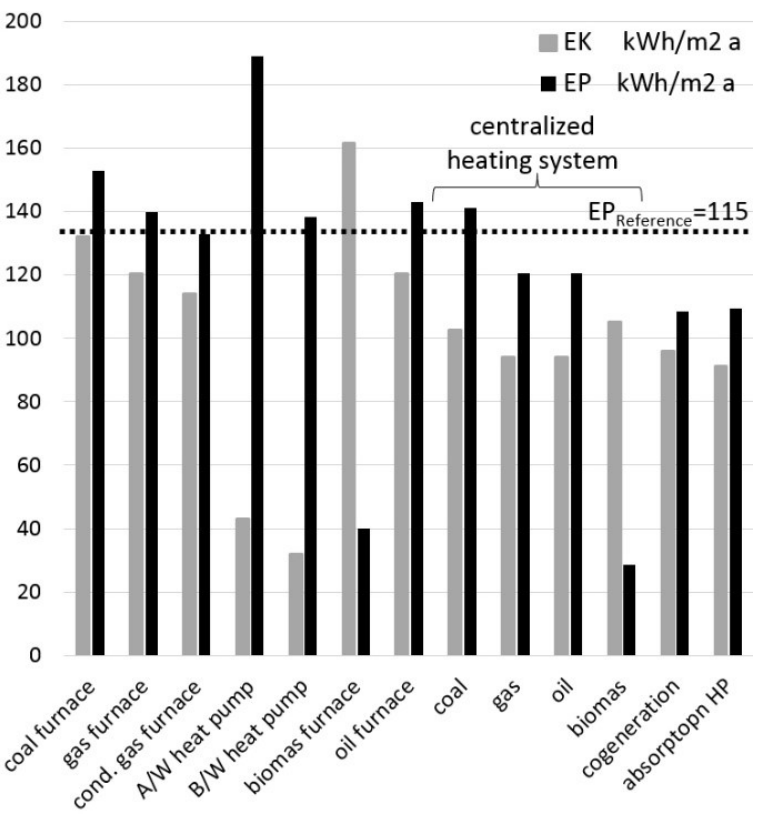

Fig. 2. EK and EP factors for selected energy sources and installation types.

system leaks and the emission of refrigerants to the atmosphere should be additionally taken into consideration. Such emission should be converted into equivalent $\mathrm{CO}_{2}$ in a form of TEWI (Rabczak, S. 2012). TEWI volumes for the same thermal power of a heat pump - commensurate with the building analysed - were presented in Table 4.

Traditionally used refrigerants are most dangerous for the atmosphere. Because a heat pump is driven by electric energy, the total emission from the heat pump, when taking into consideration the amount of fuel necessary to be used in the power plant for the need of the heat pump, may vary. It seems justified to apply natural refrigerants which are not derivatives of carbohydrates or possibly mediums which have no chloride or fluoride, and optimally also hydrogen, so as to fully eliminate their adverse influence on the stratospheric layer of the atmosphere and to minimize

Table 4. Annual emissions of refrigerants into the atmosphere from the heat pump in terms of $\mathrm{CO}_{2}$ equivalent

\begin{tabular}{|c|c|}
\hline Refrigerant & TEWI ton $\mathrm{CO}_{2} / \mathrm{a}$ \\
\hline R600a & 0.008 \\
\hline R134a & 0.536 \\
\hline R143a & 1.744 \\
\hline R404A & 1.567 \\
\hline R407C & 0.701 \\
\hline R410A & 0.825 \\
\hline R507A & 1.608 \\
\hline
\end{tabular}


their dangerous properties for human organisms. However, with the improving of indices concerning the environment, energy efficiencies of heat pump systems decrease. $\mathrm{CO}_{2}$ emission generated in a power plant from hard coal as a fuel result in almost 2-3 times as low pollution of this kind to the atmosphere as fuels such as gas or black coal, which, with the existing considerable amounts of this source, may pose a serious problem to the commercial power industry (Tymkow. P. 2013).

Final $\mathrm{CO}_{2}$ emissions from particular systems depending on a type of fuel used to generate thermal and electric energy were presented in Table 5 and 6.

Highest emissions in case of individual heating systems are achieved from the operation of systems based on coal, oil and gas furnaces. It may come as a surprise that a heat pump which is so propagated in environments connected with alternative energy sources may achieve highest $\mathrm{CO}_{2}$ emissions out of all analysed cases, especially if electric energy used to operate such pump is supplied from a coal power plant. Therefore, it points to the conclusion that a compressor heat pump is a solution which supports ecological activities only if the production of electric energy needed to supply such pump is based on a low
$\mathrm{CO}_{2}$ emission factor, such as biomass, photovoltaic cells, nuclear power or water power. Remaining power systems which provide electric energy for a compressor transform the solution with a heat pump to a solution which is most undesirable in ecological terms.

When analysing the remaining solutions used in systems supplying heat to buildings, the advantage of heat distribution systems compared to decentralized systems is easily noticeable with regard to their lower $\mathrm{CO}_{2}$ emission to the atmosphere. Solutions based on relatively not very popular solutions of absorption heat pumps belong to systems which are sensitive to electric energy sources. Depending on a type of fuel, almost a twice low $\mathrm{CO}_{2}$ emission can be achieved when using brown coal, gas or biogas. To answer the question which systems, centralized or decentralized ones, are more friendly with regard to supporting ecological attitudes of thermal energy consumers, commercial power systems should be given priority. An exception to the above answer may be the production of electric energy from renewable energy sources, biomass, biogas or nuclear power, thanks to which solutions based on heat pumps seem more attractive to the environment.

Table 5. Amount of total $\mathrm{CO}_{2}$ emissions for selected installations in $\mathrm{Mg} / \mathrm{a}$.

\begin{tabular}{|c|c|c|c|c|c|c|c|}
\hline \multicolumn{8}{|c|}{ Individual heating systems } \\
\hline Energy source & coal & gas & cond. gas & A/W HP & $\mathrm{B} / \mathrm{W}$ HP & biomas & oil \\
\hline \multicolumn{8}{|c|}{ Electric energy source } \\
\hline Black coal & 12.6 & 6.5 & 5.8 & 14.1 & 10.3 & 0.6 & 8.9 \\
\hline Hard coal & 12.7 & 6.5 & 5.9 & 16.0 & 11.7 & 0.6 & 9.0 \\
\hline Gas & 12.4 & 6.2 & 5.6 & 8.3 & 6.1 & 0.3 & 8.5 \\
\hline Oil & 12.5 & 6.3 & 5.7 & 11.4 & 8.3 & 0.5 & 8.7 \\
\hline Biomas & 12.0 & 5.9 & 5.3 & & & & 8.1 \\
\hline Biogas & 12.3 & 6.2 & 5.6 & 3.9 & 1.8 & 0.3 & 8.5 \\
\hline Atom & 12.0 & 5.9 & 5.3 & & & & 8.1 \\
\hline
\end{tabular}

Table 6. Amount of total $\mathrm{CO}_{2}$ emissions for selected installations in $\mathrm{Mg} / \mathrm{a}$. continued

\begin{tabular}{|l|c|c|c|c|c|c|}
\hline \multicolumn{9}{|c|}{ System heat } & \multicolumn{2}{c|}{ Other systems } \\
\hline Energy source & coal & gas & oil & biomas & Cogene-ration & HPt. \\
\hline \multicolumn{7}{|c|}{ Electric energy source } \\
\hline Black coal & 10.0 & 4.9 & 6.5 & 0.6 & & 9.5 \\
\hline Hard coal & 10.0 & 5.0 & 6.6 & 0.6 & & 4.6 \\
\hline Gas & 9.7 & 4.7 & 6.3 & 0.3 & 6.6 & 6.3 \\
\hline Oil & 9.9 & 4.8 & 6.4 & 0.5 & & 4.5 \\
\hline Biomas & 9.4 & 4.4 & 6.0 & & & \\
\hline Biogas & 9.7 & 4.7 & 6.3 & 0.3 & & \\
\hline Atom & 9.4 & 4.4 & 6.0 & & & \\
\hline
\end{tabular}




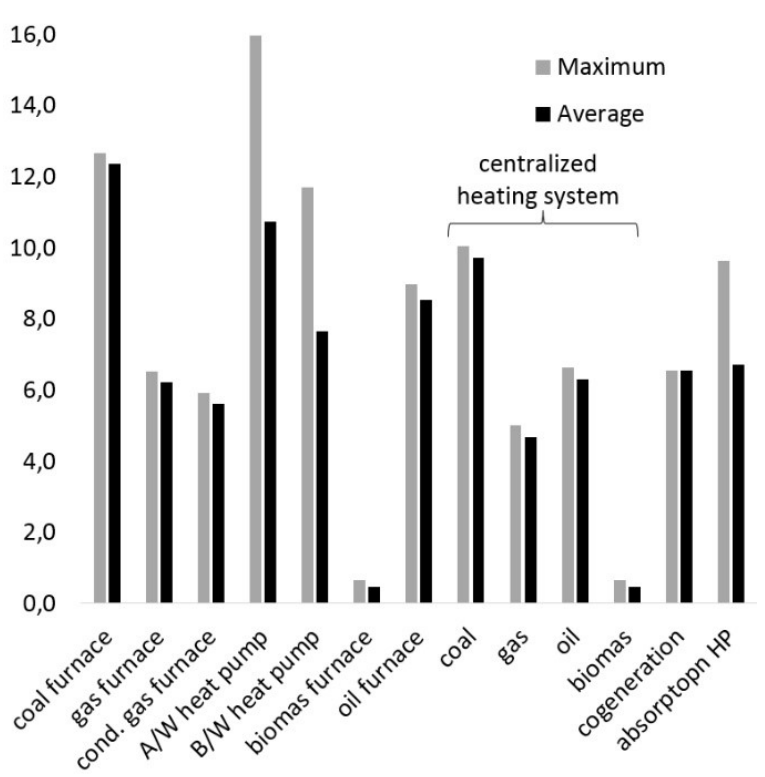

Fig. 3. $\mathrm{CO}_{2}$ emissions for the analyzed cases of installation - the maximum and average value.

To give a general picture of the situation, Figure 3 presents average and maximal values of $\mathrm{CO}_{2}$ emissions from the analysed systems, averaging emissions from particular systems which generate electric energy necessary to drive auxiliary devices in thermal energy production systems.

In this combination, the best is the system with biomass as a fuel, irrespective of whether the thermal energy production was for individual purposes or on a large scale. The previous tendency of centralized heat distribution systems as solutions supporting the reduction of $\mathrm{CO}_{2}$ emission is also confirmed.

\section{CONCLUSION}

The analysis of several variants of building heating systems showed that a heat pump commonly regarded as ecological has no satisfactory results with regard to $\mathrm{CO}_{2}$ emission. The main reason for that is a great demand for electric energy needed for the pump to operate and great dependence on an energy origin, considering a type of fuel. Energy originated from popular sources such as a coal power plant is connected with significant amounts of carbon dioxide emitted to the atmosphere. Such emission may be highest for power plants which use a material popular in the commercial power industry, that is brown coal. A heat pump as such does not emit contamination but sources generating electric energy which are necessary to power the compressor do. In order to reduce the emission and to make a heat pump friendly to the environment, auxiliary power should be achieved from biomass, biogas, nuclear power plants or renewable sources (Roaf. S. 2013). It should be noted that most electric energy in Poland comes from coal power plants and, to a smaller degree, from gas power plants. Other types of fuel and renewable energy as such constitute a marginal percentage of electric energy production. It should also be emphasized that thermal energy production has an advantage in centralized systems over individual systems because they have lower emissions of the analysed pollution to the atmosphere. Such advantage is recorded irrespective of an electric energy source necessary for the heating systems to operate.

From the presented study it may be concluded explicitly that some systems absolutely adversely affect the natural environment. However, it should be remembered that $\mathrm{CO}_{2}$ emissions coming from all human activities to the atmosphere constitute a fraction of emissions which result from natural processes taking place on the globe. Moreover, $\mathrm{CO}_{2}$ is a gas which is required in the process of photosynthesis, necessary to preserve the whole world of flora on the surface of the Earth. Therefore, a term of balanced development aiming at rational economy of environmental sources and keeping them in the best condition for future generations is so important in today's perception of threats connected with degradation of the environment.

\section{REFERENCES}

1. $\mathrm{CO}_{2}$ emissions from fuel combustion. Highlights. 2015. Paris. International Energy Agency.

2. Macknick J. 2011. Energy and $\mathrm{CO}_{2}$ emission data uncertainties. Carbon Management. 2(2), 189-205.

3. PN-EN ISO 13790: 2008. Energy performance of buildings - Calculation of energy consumption for heating and cooling.

4. Rabczak S. 2012. Heat pump and greenhouse effect. Construction and environmental engineering, z.59, t.4, 121-132.

5. Roaf S. 2013. Ecohouse, a design guide. Routledge. Taylor \& Francis Group. London.

6. Tymkow P. 2013. Building services design for energy efficient buildings. Taylor \& Francis Group. New York. 